Check for updates

Cite this: RSC Adv., 2018, 8, 4239

\title{
The utilization of a three-dimensional reduced graphene oxide and montmorillonite composite aerogel as a multifunctional agent for wastewater treatment $\uparrow$
}

\author{
Yunyun Zhang, ${ }^{a}$ Xueru Yan, ${ }^{a}$ Yayuan Yan, ${ }^{a}$ Dengjie Chen, ${ }^{a}$ Langhuan Huang, ${ }^{a}$ \\ Jingxian Zhang, ${ }^{a}$ Yu $\mathrm{Ke}^{\mathrm{b}}$ and Shaozao Tan (D) *a
}

\begin{abstract}
Mankind has witnessed a dramatically growing challenge regarding water pollution during the past decades. Meanwhile, intensive attention has been paid to developing functional materials which can comprehensively treat wastewater which always includes bacteria, organic and inorganic contaminants. In this work, a reduced graphene oxide and montmorillonite composite ( $\mathrm{KGO}-\mathrm{MMT}$ ) aerogel was synthesized by a one-step green method to treat multiple pollutants in wastewater. The Langmuir isotherm model and the pseudo-second-order kinetic model were well fitted to the adsorption of both dyes and heavy metal ions. The rGO-MMT aerogel exhibited $97.31 \%$ and $94.87 \%$ removal efficiencies for methylene blue (MB) and $\mathrm{Cr}(\mathrm{VI})$, respectively. In addition, the antibacterial ratios of the $\mathrm{rGO}-\mathrm{MMT}$ loaded with quaternary ammonium salt reached $91.57 \%$ and $95.53 \%$ for $E$. coli and S. aureus, respectively. Our results demonstrated that the aerogel had a high multi-component adsorption capacity and antibacterial activity. Attractively, the rGO-MMT aerogel exhibited excellent recyclable properties thanks to its special three-dimensional structure with outstanding mechanical strength.
\end{abstract}

Received 6th December 2017 Accepted 10th January 2018

DOI: $10.1039 / c 7 r a 13103 h$

rsc.li/rsc-advances
High-efficient adsorbent is one of the research focuses to resolve wastewater problem. Several types of materials have been investigated as adsorbents to adsorb dyes and metal ions from wastewater, including activated carbon, montmorillonite (MMT), chitosan, clay mineral, chitosan, graphene oxide (GO), reduce graphene oxide (rGO), and their composites. ${ }^{22-24}$ Although these materials have shown excellent adsorption properties, their activity is limited in killing or inhibiting pathogens. Therefore, it has drawn intensive attention to develop adsorption material that shows antimicrobial activity for water purification. rGO, a new carbon-based material, exhibits excellent performances like high surface area, strong mechanical strength and rich surface chemistry, so it has received increasing attention..$^{25}$ Among various rGO materials, rGO aerogel is three-dimensional (3D) porous network (held together by $\pi-\pi$ interaction and hydrogen bonding) with large specific surface area, low density and plentiful interpenetrating pore structure. Hence, it is used in the removal of oil and other organic solvents in water, which is economical and efficient. ${ }^{26,27}$ For example, Guo et al. prepared chitosan-graphene oxide aerogel whose adsorption capacity of oil is $900 \mathrm{~g} \mathrm{~g}^{-1}$, so it can be used to treat the industrial oil leakage or effluent in the natural water. ${ }^{28} \mathrm{MMT}$ is one type of layered silicate, and it has attracted extensive attention due to its abundance in various industries and low cost. ${ }^{29}$ In view of it, it would be significant to synthesize an rGO and MMT complex to resolve wastewater problem.
${ }^{a}$ Guangdong Engineering and Technology $R \& D$ Center of Graphene or Its Like Materials and Products, Department of Chemistry, Jinan University, Guangzhou 510632, P. R. China. E-mail: tsztan@jnu.edu.cn

${ }^{b}$ Department of Biomedical Engineering, Jinan University, Guangzhou 510632, P. R. China

$\dagger$ Electronic supplementary information (ESI) available. See DOI: $10.1039 / \mathrm{c} 7 \mathrm{ra} 13103 \mathrm{~h}$ 
In this work, we synthesized a three-dimensional reduced graphene oxide and montmorillonite composite (rGO-MMT) aerogel with multi-component adsorption capacity and antibacterial activity. More importantly, the three-dimensional aerogel could sustain its initial structure after vigorous shaking when it was reused. Therefore, the three-dimensional rGO-MMT aerogel was a potential candidate as efficient adsorbent in water purification.

\section{Experimental}

\section{Synthesis of rGO-MMT aerogel}

GO originated from graphite powder was synthesized using a modified Hummers method. ${ }^{30,31}$ The rGO-MMT aerogel was obtained by sol-gel method. Briefly, GO powder $(30 \mathrm{mg})$ and ascorbic acid (30-45 mg) were added into $10 \mathrm{~mL}$ of ultrapure water (>18 M $\Omega$ ). Meanwhile, $4 \mathrm{~mL}$ of MMT aqueous solution with the content ranging from $2 \mathrm{wt} \%$ to $6 \mathrm{wt} \%$ was added in order to optimize the concentration. After ultrasonic treatment for $0.5 \mathrm{~h}$, the mixed solution was transferred into a $25 \mathrm{~mL}$ glass bottle with cover and heated at $95{ }^{\circ} \mathrm{C}$ for $6 \mathrm{~h}$ (for antibacterial experiment, $1 \mathrm{~mol}$ of dodecyl dimethyl benzyl ammonium chloride (1227) was added to the mixed solution). Then, rGOMMT hydrogel and 1227-loaded rGO-MMT hydrogel were

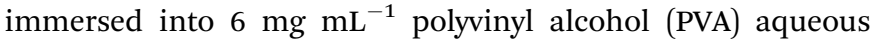
solution for 2 days. Finally, the hydrogel was washed with ultrapure water for several times, and then fully freeze-dried at $-55{ }^{\circ} \mathrm{C}$ for $12 \mathrm{~h}$ to acquire rGO-MMT aerogel and rGO-MMT1227 aerogel.

\section{Characterizations}

X-ray diffraction (XRD) patterns were obtained using $\mathrm{X}$-ray analyzer (MSAL-XD2) with a $\mathrm{Cu} \mathrm{K} \alpha$ radiation source $(\lambda=1.5405 \AA)$ at a voltage of $48 \mathrm{kV}$ and a current of $30 \mathrm{~mA}$. Characterization was performed under the $2 \theta$ range of 5.0-80.0 at a scanning rate of $2^{\circ} \mathrm{min}^{-1}$. Fourier transform infrared (FT-IR) spectra were recorded using a Nicolet 6700 spectrometer. The UV-vis spectra were measured by a Hitachi 330 UV-vis spectrophotometer. Transmission electron microscopy (TEM) images and the corresponding mappings were obtained by using Philips TECNAL-10 transmission electron microscope. Scanning electron microscopy (SEM) images and energy dispersive X-ray spectroscopy (EDX) patterns were performed on a field emission-scanning electron microscope (PHILIPS XL-30 ESEM, Netherlands). The surface area and porosity of aerogel were measured by ASAP-2010 and calculated with BrunnerEmmett-Teller (BET) method. The heavy metal content of the aqueous solution was determined by inductively coupled plasma (ICP) (Optima 2000DV).

\section{Adsorption investigation}

Removal of dye. First, stock solutions $\left(100 \mathrm{mg} \mathrm{L}^{-1}\right)$ of methyl orange (MO) and methylene blue (MB) were prepared by dissolving prescribed amounts of $\mathrm{MO}$ and $\mathrm{MB}$ with ultrapure water. The mixed aqueous solution of $\mathrm{MB}$ and MO, where the concentration of $\mathrm{MO}$ aqueous solution was fixed at $50 \mathrm{mg} \mathrm{L}^{-1}$ and the concentration of $\mathrm{MB}$ aqueous solution ranged from 5 to $50 \mathrm{mg} \mathrm{L}^{-1}$, was prepared by diluting the stock solution. Then, the rGO-MMT aerogel was put into the conical flask containing the mixed aqueous solution, and the conical flask was kept into the shaker at $150 \mathrm{rpm}$ and room temperature. $4 \mathrm{~mL}$ of suspension was collected at predetermined time interval for the analysis of residual dye concentration in the aqueous solution. The concentration of dye was determined with an UV-vis spectrophotometer.

Removal of heavy metal ion. The effect of initial concentration on the evaluation of the adsorption capacity was investigated by using $\mathrm{Cr}(\mathrm{vI})$ solution prepared from the standard stock solution $\left(100 \mathrm{mg} \mathrm{L}^{-1}\right)$. The effect of $\mathrm{pH}$ value on the adsorption capacity was also investigated in the range from 2 to 11 . The $\mathrm{pH}$ was adjusted by using $0.1 \mathrm{~mol} \mathrm{~L}^{-1}$ sodium hydroxide $(\mathrm{NaOH})$ or hydrochloric acid $(\mathrm{HCl})$ solution. Temperature was dominated in order to get the optimized adsorption. $\mathrm{Cr}(\mathrm{VI}), \mathrm{Cu}$ (II) and $\mathrm{Pb}$ (II) solutions were added together for the evaluation of the competitive adsorption of rGO-MMT aerogel. The concentration of heavy metal ion was determined with ICP.

Antibacterial activity. The antibacterial activity was evaluated on Gram-positive bacteria Staphylococcus aureus (S. aureus) and Gram-negative bacteria Escherichia coli (E. coli). First, the E. coli and $S$. aureus cells were cultured. Second, rGO-MMT, rGOMMT-1227 and pure 1227 were added into a tube and then mixed into $10^{5} \mathrm{cfu} \mathrm{mL}^{-1}$ E. coli or $S$. aureus with $0.85 \%$ saline. Then, all samples were immersed into bacteria at $37{ }^{\circ} \mathrm{C}$ in an orbital shaker for $24 \mathrm{~h}$. Afterwards, immersed suspensions were inoculated to the medium of nutrient agar in incubator at $37{ }^{\circ} \mathrm{C}$ for $24 \mathrm{~h}$. Finally, the antibacterial activity was evaluated by the reduction percentage of microorganism $(R \%)$.

$$
R \%=(A-B) \div A \times 100 \%
$$

where $A\left(\mathrm{cfu} \mathrm{mL} L^{-1}\right)$ and $B\left(\mathrm{cfu} \mathrm{mL}^{-1}\right)$ stood for the untreated sample and the treated sample, respectively, measured at the indicated contact time.

\section{Results and discussion}

\section{Characterization of aerogel}

According to the digital photos of rGO-MMT aerogel (Fig. 1a and b), it was obviously that the volume of rGO-MMT aerogel was larger than that of rGO aerogel. The compressive strength of rGO-MMT aerogel was examined as shown in Fig. 1c. Fig. 1d depicted a digital image of kapok with rGO-MMT aerogel was placed on the top. The insignificant deformation of kapok indicated the low density of the rGO-MMT aerogel.

XRD patterns of GO, rGO, MMT and rGO-MMT aerogel were shown in Fig. 2a. For GO, a diffraction peak at $2 \theta=10.30^{\circ}$ was observed, and the calculated interlayer spacing was $0.87 \mathrm{~nm}$, corresponding to the (001) plane. Meanwhile, a new broad diffraction peak at $2 \theta=24.9^{\circ}$ was observed for the reduced GO, revealing the successful formation of rGO. For MMT, a welldefined diffraction peak at $2 \theta=6.12^{\circ}$ appeared, which indicated the formation of a calcium montmorillonite. ${ }^{32}$ The diffraction pattern of rGO-MMT aerogel contained the 

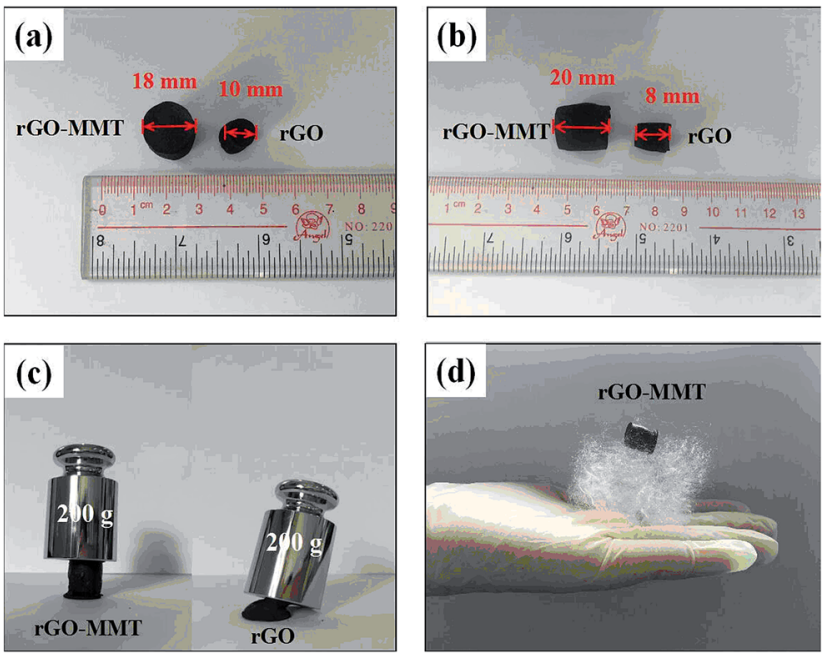

Fig. 1 The digital photos of rGO-MMT aerogel.

diffraction peaks of both rGO and MMT, indicating the successful incorporation of MMT into rGO. FT-IR spectra of GO, rGO, MMT and rGO-MMT aerogel were shown in Fig. 2b. The strong peak at $3452 \mathrm{~cm}^{-1}$ was attributed to the stretching vibration of the $\mathrm{O}-\mathrm{H}$. The peaks at 1731, 1621, 1384 and $1049 \mathrm{~cm}^{-1}$ could be assigned to the $\mathrm{C}=\mathrm{O}, \mathrm{C}-\mathrm{H}-\mathrm{O}, \mathrm{C}=\mathrm{C}$ and $\mathrm{C}-$ $\mathrm{O}-\mathrm{C}$, respectively. However, the $\mathrm{O}=\mathrm{C}-\mathrm{O}$ was negligible for $\mathrm{rGO}$. The abundance of oxygen-containing functional group was much more on GO than that on rGO. For the FT-IR spectrum of MMT, the peaks at 3620 and $796 \mathrm{~cm}^{-1}$ corresponded to the stretching vibrations of the $\mathrm{Al}-\mathrm{OH}$ and $\mathrm{Si}-\mathrm{O}$ groups, and the strong speaks at 1089 and $1035 \mathrm{~cm}^{-1}$ originated from the $\mathrm{Si}-\mathrm{O}$ vibration of amorphous silica and the tetrahedral sheet. Furthermore, the bands at 914, 844, 624 and $518 \mathrm{~cm}^{-1}$ were ascribed to deformation vibrations of $\mathrm{Al}-\mathrm{Al}-\mathrm{OH}, \mathrm{Al}-\mathrm{Mg}-\mathrm{OH}$ and Si-O-Al. For rGO-MMT aerogel, all peaks belonging to rGO and MMT appeared simultaneously, and the intensity of the peak belonging to rGO became weak. These results demonstrated that rGO and MMT were combined together successfully.
The $\mathrm{N}_{2}$ adsorption-desorption isotherms of rGO, rGO-MMT0.02, rGO-MMT-0.04 and rGO-MMT-0.06 aerogels (Fig. S1†) exhibited type IV isotherms, according to the IUPAC classification. ${ }^{33}$ According to the Table $\mathrm{S} 1$ and Fig. $\mathrm{S} 2 \uparrow$ the application of $0.04 \mathrm{wt} \%$ MMT was beneficial for the dispersion of rGO and the enhanced adsorption capability. Thus, rGO-MMT-0.04 was selected in subsequent experiments.

According to the SEM and TEM images (Fig. 3 and 4), there were many apparent wrinkles on the surface of rGO due to the scrolled rGO sheets. Fig. 3b, c, $4 \mathrm{~d}$ and $3 \mathrm{e}$ showed that the surface of rGO-MMT aerogel was quite loose with large pore compared to rGO aerogel. The EDX (Fig. 3f) and mapping (Fig. 4d) results of rGO-MMT aerogel suggested the existence of $\mathrm{C}, \mathrm{O}, \mathrm{Mg}, \mathrm{Al}, \mathrm{Si}$ and $\mathrm{Ca}$ elements. According to the nominal existence of $\mathrm{Mg}, \mathrm{Al}, \mathrm{Si}$ and Ca elements, it could be inferred that the small particles on rGO-MMT aerogel were MMT. ${ }^{32}$

\section{Adsorption experiments}

Adsorption of dye. The adsorption experiment of MO was performed at room temperature without adjusting pH. rGOMMT aerogel was added to $200 \mathrm{~mL}$ of $\mathrm{MO}$ solutions with different concentrations ranging from 5 to $50 \mathrm{mg} \mathrm{L}^{-1}$.

Fig. 5a showed the removal of MO with different contact time. The results indicated that there was a rapid uptake within the first $20 \mathrm{~min}$ and then the trend became smooth. This phenomenon indicated that the surface of adsorbent was gradually blocked by dye molecules during the adsorption process, and then the surface was completely covered after certain time. ${ }^{34}$ The adsorption curves showed that rGO-MMT rapidly adsorbed $\mathrm{MO}$ at the concentration of $50 \mathrm{mg} \mathrm{L}^{-1}$, so this concentration of MO was applied in the mixed aqueous solution in subsequent experiments.

The selective adsorption of $\mathrm{MB}$ from mixed aqueous solution was studied, where the MO aqueous solution $\left(50 \mathrm{mg} \mathrm{L}^{-1}, 200\right.$ $\mathrm{mL}$ ) was mixed with different concentrations of $\mathrm{MB}$ aqueous solution (from 5 to $50 \mathrm{mg} \mathrm{L}^{-1}$ ). As shown in Fig. $5 \mathrm{~b}$, the influence of temperature $\left(30{ }^{\circ} \mathrm{C}, 40{ }^{\circ} \mathrm{C}\right.$ and $\left.50{ }^{\circ} \mathrm{C}\right)$ on the selective adsorption capacity of $\mathrm{MB}\left(C_{0}=40 \mathrm{mg} \mathrm{L}^{-1}\right)$ was investigated. A
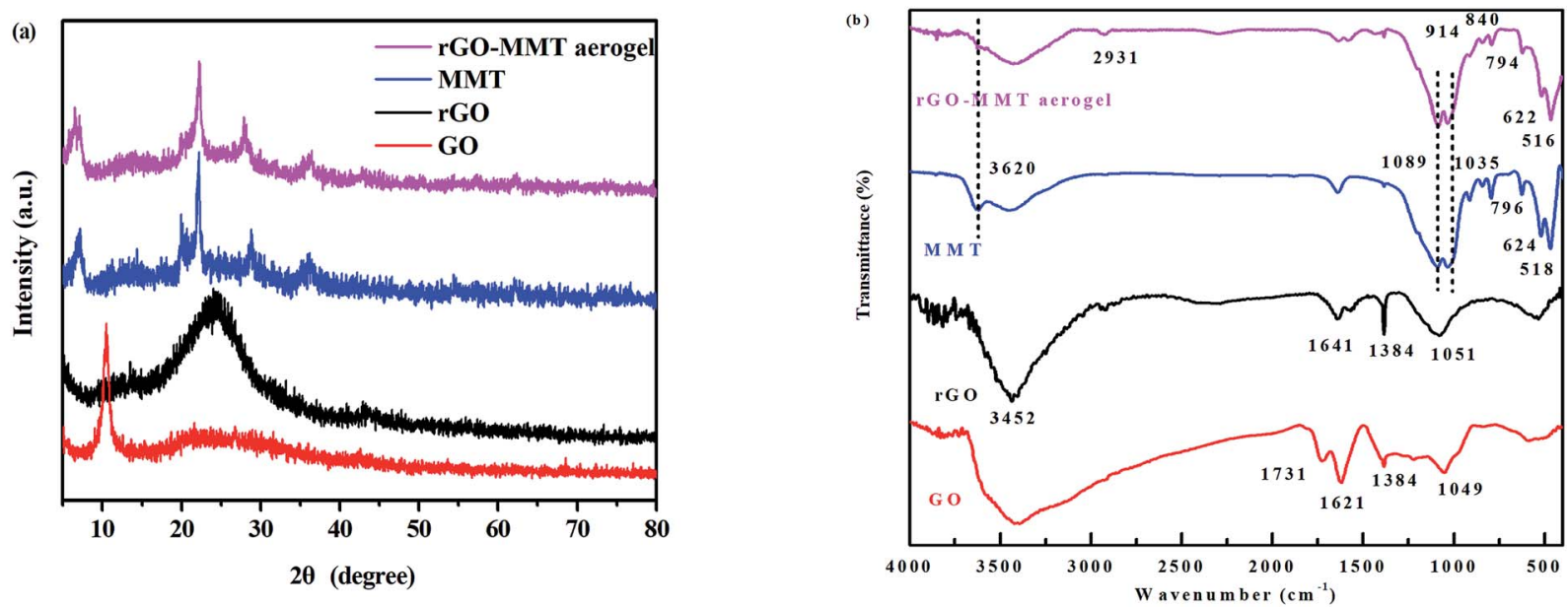

Fig. 2 XRD patterns of $r G O, G O, M M T$ and rGO-MMT aerogel (a), FT-IR spectra of GO, rGO, MMT and rGO-MMT aerogel (b). 

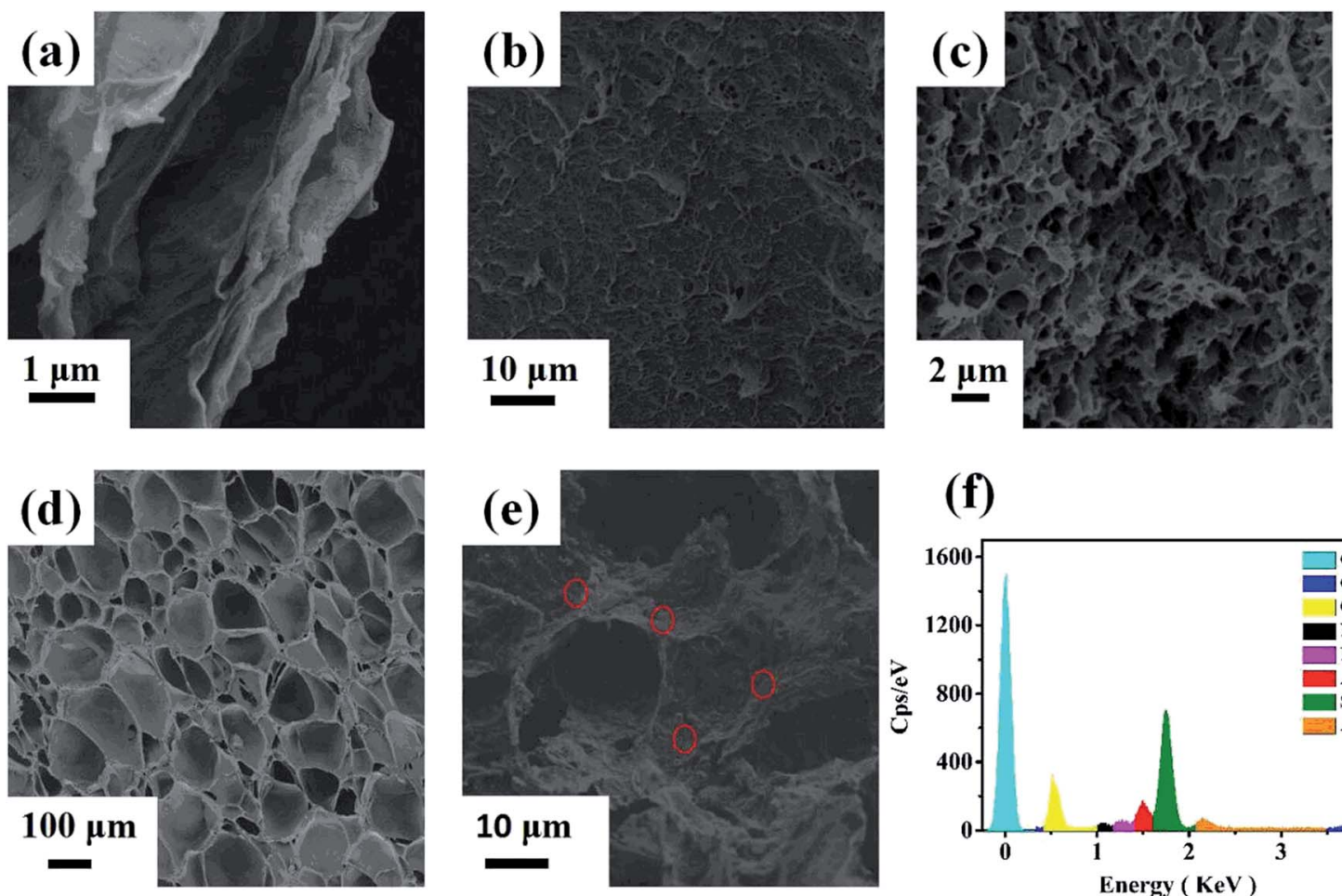

(f)

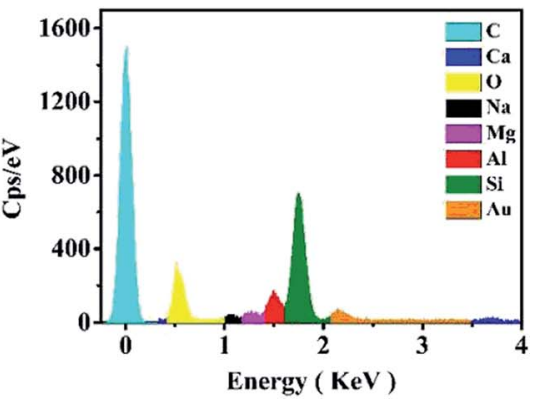

Fig. 3 SEM images of rGO (a), rGO aerogel ( $b$ and $c$ ) and rGO-MMT aerogel ( $d$ and e). EDS of rGO-MMT aerogel ( $f$ ).
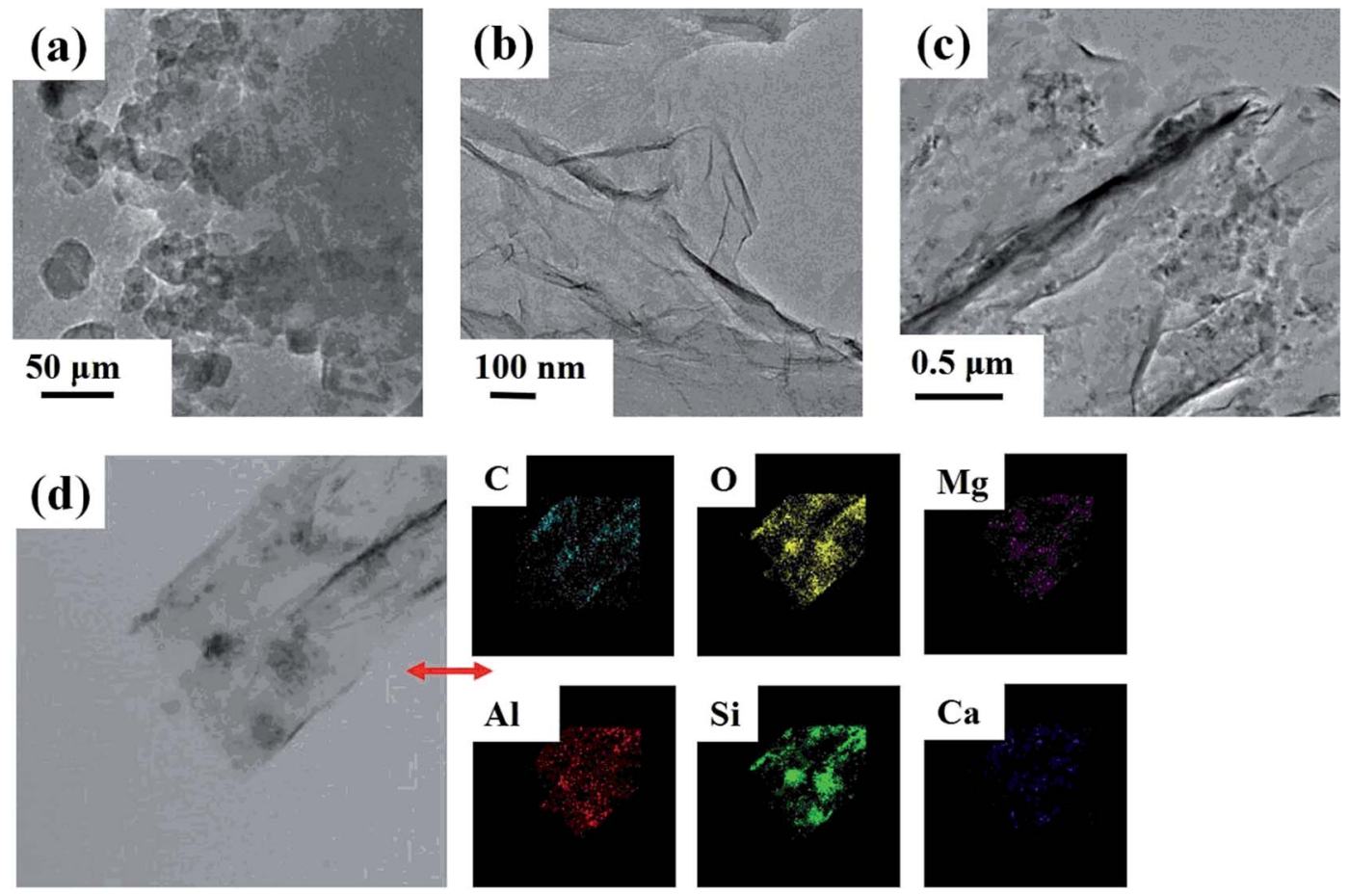

Fig. 4 TEM images of MMT (a), rGO aerogel (b) and rGO-MMT aerogel (c). Mapping of rGO-MMT aerogel (d).

high temperature promoted the diffusion rate of dye molecule, which influenced the selective adsorption of MB. However, high temperature operation would increase the cost. Thus, temperature of $40{ }^{\circ} \mathrm{C}$ was adopted for the following experiments. The
$\mathrm{pH}$ in the solution might influence dye adsorption by changing the surface charge of the adsorbent and also the distribution of the dye in solution phase. ${ }^{35}$ Fig. $5 \mathrm{c}$ showed the maximum selective adsorption capacity of MB from the mixed aqueous 

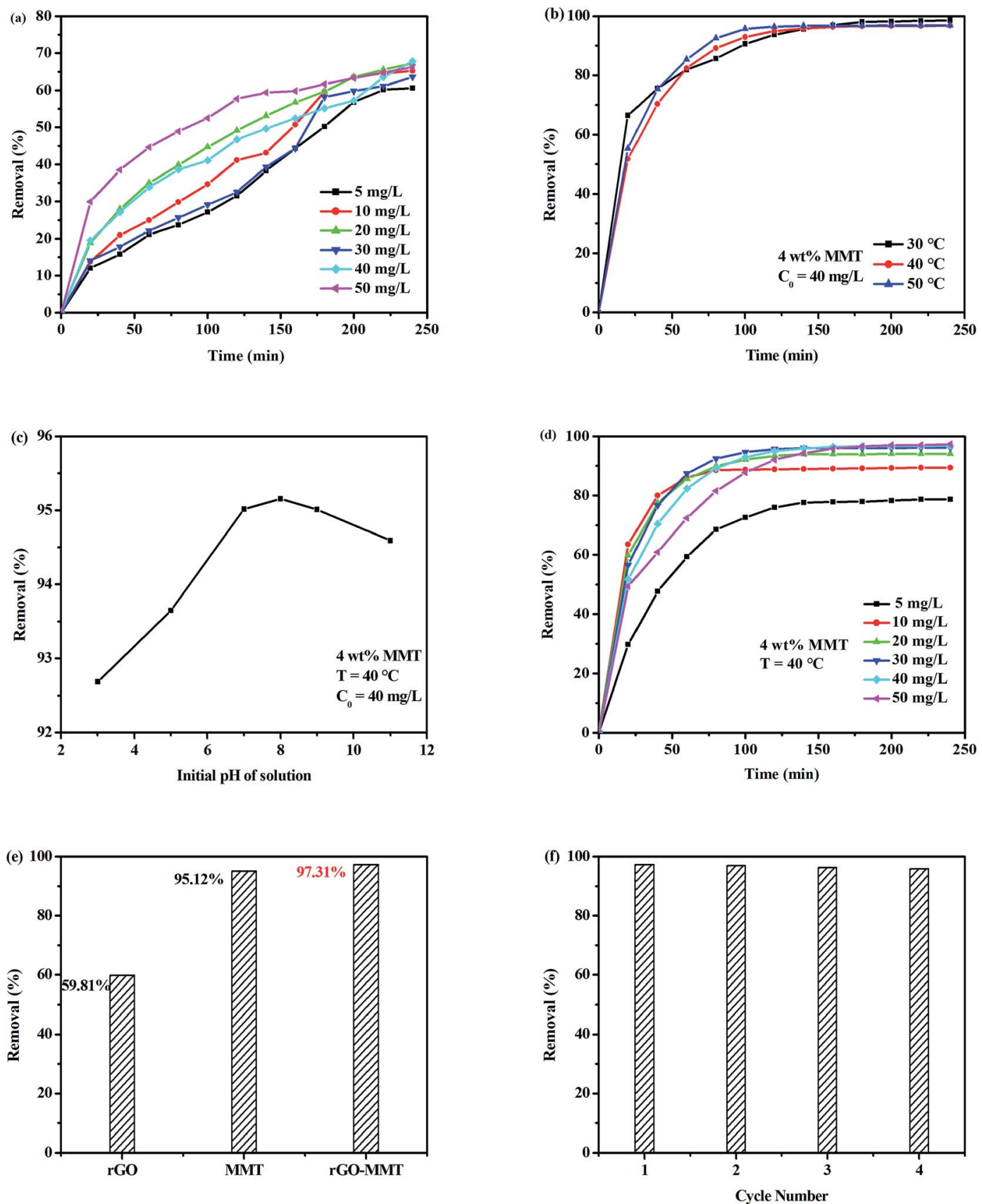

Fig. 5 Adsorption curves of $\mathrm{MO}$ (a), effects of temperature (b) and $\mathrm{pH}$ (c) on the selective adsorption of $\mathrm{MB}$, effect of the concentration on the selective adsorption of $\mathrm{MB}\left(\mathrm{pH}=8\right.$ and $T=40^{\circ} \mathrm{C}$; the concentration of $\mathrm{MO}$ was $\left.50 \mathrm{mg} \mathrm{L}^{-1}\right)(\mathrm{d})$, the selective adsorption of $\mathrm{MB}$ with $\mathrm{rGO}$ aerogel, MMT powder and rGO-MMT aerogel (e), cycle stability of $\mathrm{rGO}-$ MMT aerogel for the selective adsorption of MB ( $f$ ).

solution by $\mathrm{rGO}-\mathrm{MMT}$ aerogel at $\mathrm{pH}=8$. The selective adsorption capacity of MB from mixed aqueous solution by rGO-MMT aerogel increased with increasing $\mathrm{pH}$ when $\mathrm{pH}<8$, while the selective adsorption capacity of MB decreased with increasing $\mathrm{pH}$ from 8 to 11. Hydroxyl ions increased, and negative charges of hydroxyl ions competed with negative charges of rGO-MMT aerogel about MB. While we analyzed residual dye concentration in the aqueous solution. There were little MB combined by hydroxyl ions in aqueous solution, so the selective adsorption capacity of MB decreased. The adsorption curves showed that $\mathrm{rGO}-\mathrm{MMT}$ largely adsorbed $\mathrm{MO}$ at the concentration of $50 \mathrm{mg} \mathrm{L}^{-1}$ (Fig. $5 \mathrm{~d}$ ). Thus, temperature of $40{ }^{\circ} \mathrm{C}, 4 \mathrm{~h}, \mathrm{pH}=8$ and the concentration of $50 \mathrm{mg} \mathrm{L}^{-1}$ were selected in subsequent experiments.

Fig. 5e presented the comparison of MB selective removal rate by rGO-MMT aerogel, pristine MMT powder and rGO aerogel. rGO-MMT showed the highest removal rate of $\mathrm{MB}$ compared with rGO and MMT. rGO showed negligible removal rate of MB, while the removal rate of MB on MMT was $95.12 \%$. It was difficult to recollection for suspended MMT powder in 
solution. From Fig. 5f, after four adsorption/desorption cycles, it was observed that in the first cycle the selective removal rate of $\mathrm{MB}$ onto the rGO-MMT aerogel was $97.31 \%$ at $40{ }^{\circ} \mathrm{C}$ and $\mathrm{pH}=$ 8. Moreover, after four absorption/desorption cycles the removal rate still remains at $95.87 \%$, which just reduced $1.44 \%$ compared with that of the first cycle. Remarkably, after four times cycles, the aerogels could still maintain their 3D structure. This showed that aerogel could be an environmental, highefficient adsorbent for selective removing MB.

In this study, Langmuir (1) and Freundlich isothermal models (2) were used to understand the thermodynamics of selective adsorption of $\mathrm{MB} .^{36,37}$

$$
\begin{gathered}
\frac{C_{\mathrm{e}}}{Q_{\mathrm{e}}}=\frac{1}{Q_{\mathrm{m}} k_{\mathrm{L}}}+\frac{C_{\mathrm{e}}}{Q_{\mathrm{m}}} \\
\log Q_{\mathrm{e}}=\log k_{\mathrm{F}}+\frac{1}{n} \log C_{\mathrm{e}}
\end{gathered}
$$

Table 1 Langmuir and Freundlich isotherm parameters and correlation coefficients for the selective adsorption of MB onto rGO-MMT

\begin{tabular}{lllllllll}
\hline & Langmuir & & \multicolumn{3}{l}{ Freundlich } \\
$T(\mathrm{~K})$ & $Q_{\max }\left(\mathrm{mg} \mathrm{g}^{-1}\right)$ & $K_{\mathrm{L}}$ & $R^{2}$ & & $K_{\mathrm{F}}$ & $n$ & $R^{2}$ \\
\hline 303 & 167.79 & 0.94 & 0.973 & 33.28 & 5.51 & 0.836 \\
313 & 182.15 & 0.12 & 0.979 & 33.52 & 6.04 & 0.855 \\
323 & 227.27 & 0.19 & 0.987 & 32.31 & 9.92 & 0.825
\end{tabular}

where $K_{\mathrm{L}}\left(\mathrm{L} \mathrm{mg}{ }^{-1}\right)$ was the Langmuir adsorption isotherm constant related to the adsorption energy; $K_{\mathrm{F}}\left(\mathrm{mg} \mathrm{g}^{-1}\right)$ and $1 / n$ were Freundlich constants related to the capacity and intensity of adsorption; $C_{\mathrm{e}}\left(\mathrm{mg} \mathrm{L}^{-1}\right)$ was the equilibrium value.

Kinetics analysis was deployed for a better understanding of the selective adsorption process. The pseudo-first-order and pseudo-second-order equations were further used to model the kinetics data using a linear fitting. ${ }^{36,37}$ The models were expressed in eqn (3) and (4):

$$
\begin{gathered}
\ln \left(Q_{\mathrm{e}}-Q_{t}\right)=\ln Q_{\mathrm{e}}-k_{1} t \\
\frac{t}{Q_{\mathrm{e}}}=\frac{1}{k_{2} Q_{\mathrm{e}}^{2}}+\frac{t}{Q_{\mathrm{e}}}
\end{gathered}
$$

where $k_{1}$ and $k_{2}$ were the pseudo-first-order and the pseudosecond-order rate constants; $Q_{\mathrm{e}}$ was the amount of MB adsorbed at equilibrium $\left(\mathrm{mg} \mathrm{g}^{-1}\right) ; Q_{t}\left(\mathrm{mg} \mathrm{g}^{-1}\right)$ was the amount of the selective adsorption varying with time.

The fitted parameters in Langmuir and Freundlich models for selective adsorption were shown in Table 1. By comparing the $R^{2}$ values of both models, Langmuir model was better to describe the selective adsorption onto the rGO-MMT aerogel than Freundlich model, suggesting the monolayer or homogeneous adsorption for $\mathrm{MB} .{ }^{37}$

The kinetics data of the adsorbent were fitted to the pseudofirst and second-order model, as shown in Fig. 6. The calculated kinetics parameters from two models were listed in Table 2. In Fig. 6a and b, the pseudo-second-order model displayed a good

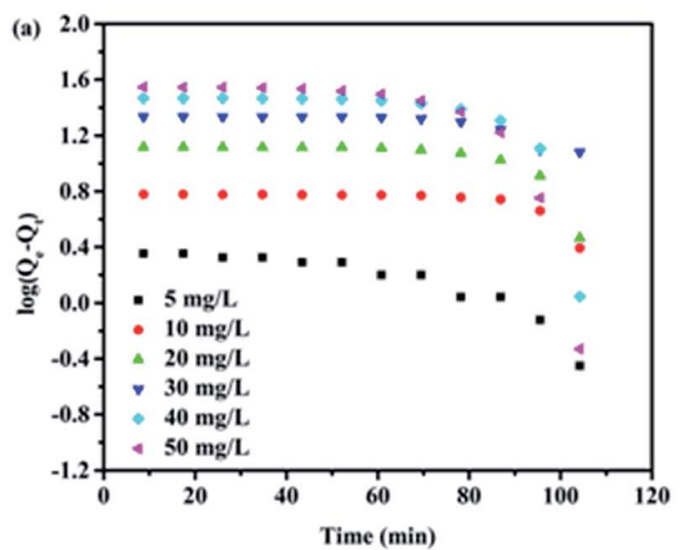

\begin{tabular}{|c|c|c|c|c|c|c|}
\hline 10 & 0.0053 & 7.23 & 0.415 & 0.00035 & 6.94 & 0.999 \\
\hline 20 & 0.0092 & 18.12 & 0.442 & 4.46 & 14.45 & 0.999 \\
\hline 30 & 0.0053 & 25.95 & 0.606 & 1.47 & 25.19 & 0.984 \\
\hline
\end{tabular}

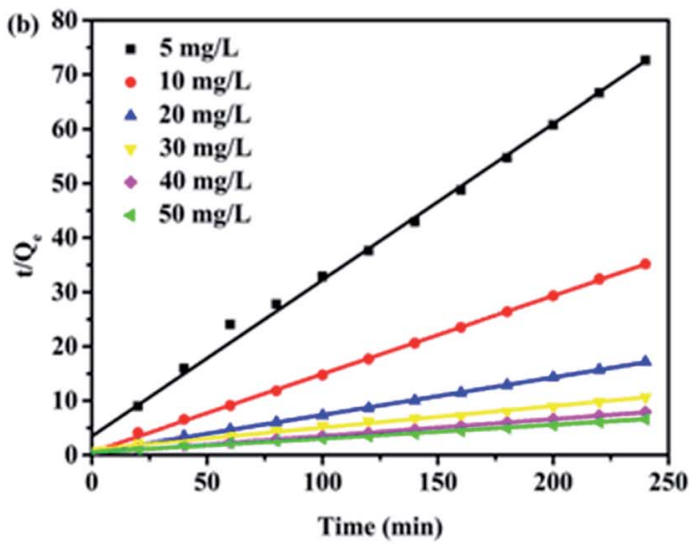

Fig. 6 Pseudo-first-order (a) and pseudo-second-order (b) equations in the modeling of adsorption kinetics.

Table 2 Kinetic parameters for the selective adsorption of MB onto the rGO-MMT aerogel in aqueous solution 
fit with the selective adsorption of MB on rGO-MMT aerogel, while the pseudo-first-order model did not fit well, suggesting that the selective adsorption process might be based on chemisorption, involving valence force via sharing or exchanging electron between adsorbent and adsorbate. ${ }^{38}$ As known, the abundant functional groups were located in rGO-MMT aerogel, such as hydroxy groups, epoxide groups and carboxylic groups. Accordingly, MB could be adsorbed via interaction between MB molecule and these functional groups of rGO in the rGO-MMT aerogel.

Adsorption of heavy metal ion. We had shown that the rGOMMT aerogel had the ability to adsorb organic pollutants. In this part, the possibility of removing heavy metal ion from waste water was investigated.
Fig. 7a showed the effects of initial concentration and contact time on the removal rate. It was evident that the adsorption of heavy metal ion on the aerogel increased gradually with increasing contact time. Therefore, we selected the contact time of $4 \mathrm{~h}$ in this work. Totally, a low concentration of $\mathrm{Cr}$ (vi) was beneficial for improving removal rate. Fig. 7b showed that the adsorption capacities of $\mathrm{Cr}(\mathrm{vI})$ were $52.64 \%$, 92.05\%, $94.87 \%, 85.60 \%$ and $85.06 \%$ for rGO-MMT aerogel at $0{ }^{\circ} \mathrm{C}$, $20{ }^{\circ} \mathrm{C}$, room temperature $\left(35^{\circ} \mathrm{C}\right), 40^{\circ} \mathrm{C}$ and $60{ }^{\circ} \mathrm{C}$, respectively. The $\mathrm{pH}$ of the initial solution determined the charge on the surface of adsorbent and the degree of ionization and speciation of the metal ion. ${ }^{39}$ The effect of $\mathrm{pH}$ on the adsorption of $\mathrm{Cr}(\mathrm{vI})$ was evaluated by changing the initial $\mathrm{pH}$ from 2 to 11 .
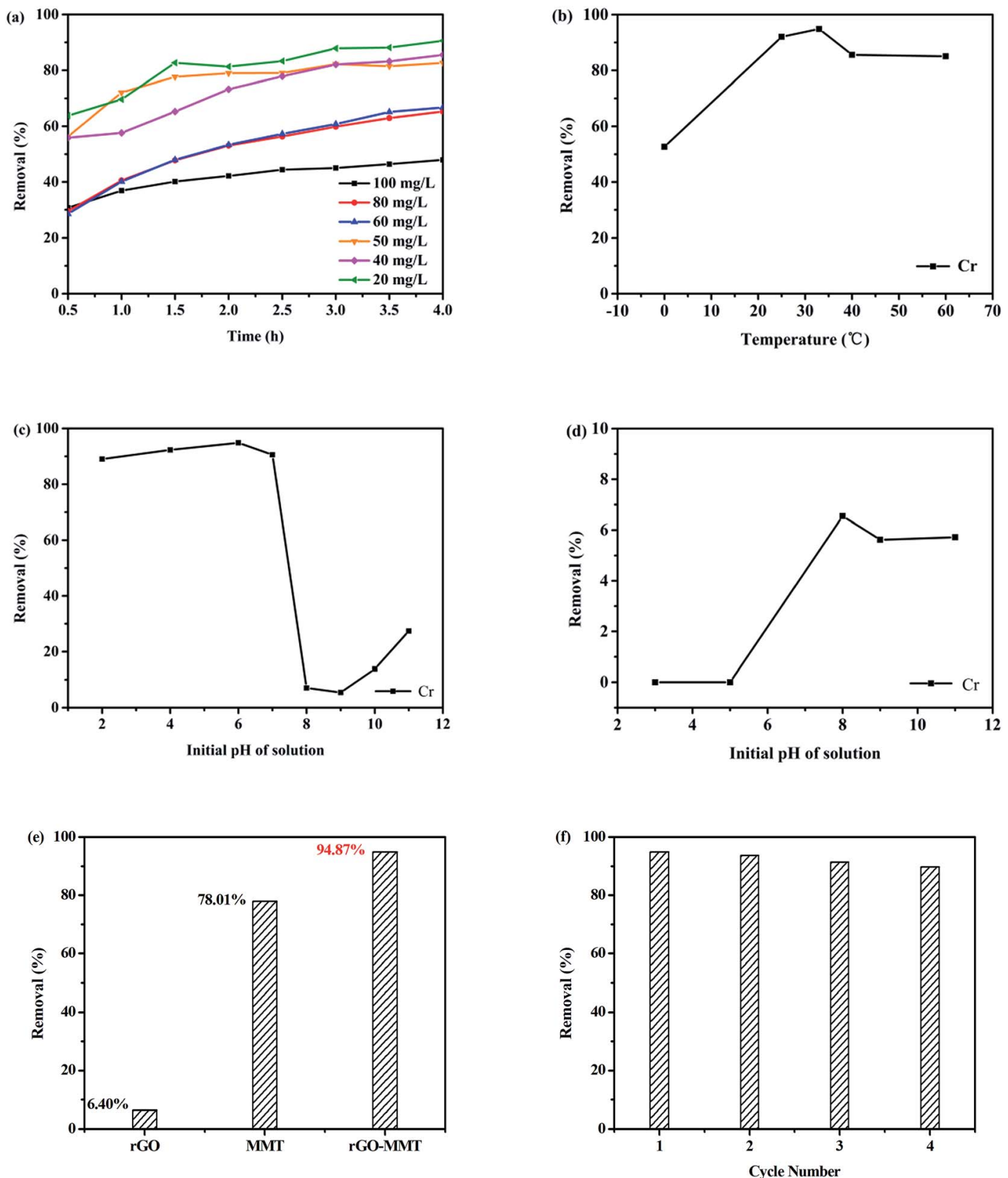

Fig. 7 Effects of initial concentration and contact time (a), temperature (b) and pH (c and d) on Cr(vi) removal with rGO-MMT, adsorption of Cr(vi) with pure rGO, MMT and rGO-MMT aerogel (e), cycle stability of rGO-MMT aerogel for the removal of $\mathrm{Cr}(\mathrm{vI})$ (f). 
According to Fig. 7c and d, maximum removal rate of metal ion could be observed at $\mathrm{pH}=6$. Under the alkaline condition, the surface of the adsorbent was surrounded with $\mathrm{OH}^{-}$that competed with $\mathrm{CrO}_{4}{ }^{2-}$. Meanwhile, $\mathrm{Cr}^{6+}$ would be reduced to $\mathrm{Cr}^{3+}$ to react with $\mathrm{OH}^{-}$, and $\mathrm{Cr}(\mathrm{OH})_{3}$ was formed. Therefore, the removal rate increased slightly when $\mathrm{pH}$ ranged from 8 to 11. In contrast, heavy metal ions were adsorbed due to the electrostatic adsorption at low $\mathrm{pH} .^{\mathbf{4 0}}$

Fig. 7e presented the comparison of $\mathrm{Cr}(\mathrm{vI})$ removal rate by rGO-MMT, pristine MMT and rGO. rGO-MMT showed the highest removal rate of $\mathrm{Cr}(\mathrm{vI})$ compared with rGO and MMT. Compared with sole rGO and MMT, the effectiveness of rGOMMT might be ascribed to a relatively large surface area, high pore volume and loose structure. We thus proposed that the synergy between rGO and MMT contributed to the enhancement of the removal rate of $\mathrm{Cr}(\mathrm{vI})$.

The adsorption of $\mathrm{Cr}(\mathrm{vI})$ was performed at $\mathrm{pH}=6,4 \mathrm{~h}$ and room temperature, and desorption with $\mathrm{NaOH}$ solution at $\mathrm{pH}=$ $13,12 \mathrm{~h}$, room temperature to evaluate the regenerate of rGOMMT. As shown in Fig. 7f. It had no obvious decrement after four recycles, suggesting the good removal stability of the aerogel. In conclusion, our results had demonstrated that environment-friendly rGO-MMT aerogel was a robust and efficient adsorbent.

To evaluate the multiple adsorption of rGO-MMT for heavy metal ions, $10 \mathrm{mg} \mathrm{L}^{-1} \mathrm{Cu}\left(\mathrm{NO}_{3}\right)_{2}, 10 \mathrm{mg} \mathrm{L}^{-1} \mathrm{~Pb}\left(\mathrm{NO}_{3}\right)_{2}$ and $20 \mathrm{mg} \mathrm{\textrm {L } ^ { - 1 }} \mathrm{K}_{2} \mathrm{Cr}_{2} \mathrm{O}_{7}$ were mixed together in the solution. As shown in Fig. S3† it was evident that rGO-MMT could not only adsorb $\mathrm{Cr}(\mathrm{VI})$, but also adsorb $\mathrm{Cu}(\mathrm{II})$ and $\mathrm{Pb}(\mathrm{II})$.

Adsorption isotherms were important for analyzing the adsorption mechanism. The Langmuir and Freundlich models

Table 3 Langmuir and Freundlich isotherm parameters and correlation coefficients for the removal of $\mathrm{Cr}(\mathrm{vI})$ with rGO-MMT

\begin{tabular}{|c|c|c|c|c|c|c|}
\hline \multirow[b]{2}{*}{$T(\mathrm{~K})$} & \multicolumn{3}{|l|}{ Langmuir } & \multicolumn{3}{|c|}{ Freundlich } \\
\hline & $Q_{\max }\left(\mathrm{mg} \mathrm{g}^{-1}\right)$ & $K_{\mathrm{L}}$ & $R^{2}$ & $K_{\mathrm{F}}$ & $n$ & $R^{2}$ \\
\hline 303 & 77.52 & 0.344 & 0.989 & 27.61 & 3.497 & 0.815 \\
\hline
\end{tabular}

Table 4 Kinetic parameters for the removal of $\mathrm{Cr}(\mathrm{vI})$ with $\mathrm{rGO}-\mathrm{MMT}$

\begin{tabular}{|c|c|c|c|c|c|c|}
\hline \multirow{2}{*}{$\begin{array}{l}\text { Initial Cr } \\
\left(\mathrm{mg} \mathrm{L}^{-1}\right)\end{array}$} & \multicolumn{3}{|c|}{ Pseudo-first-order } & \multicolumn{3}{|c|}{ Pseudo-second-order } \\
\hline & $K_{1}$ & $Q_{\mathrm{e}}\left(\mathrm{mg} \mathrm{g}^{-1}\right)$ & $R^{2}$ & $K_{2}$ & $Q_{\mathrm{e}}\left(\mathrm{mg} \mathrm{g}^{-1}\right)$ & $R^{2}$ \\
\hline 20 & 0.0135 & 9.48 & 0.9924 & 0.00176 & 29.24 & 0.998 \\
\hline 40 & 0.0152 & 38.83 & 0.9547 & 0.000490 & 58.48 & 0.992 \\
\hline 50 & 0.0191 & 27.59 & 0.8349 & 0.00109 & 66.23 & 0.999 \\
\hline 60 & 0.0157 & 67.20 & 0.9198 & 0.00205 & 75.76 & 0.987 \\
\hline 80 & 0.0142 & 73.99 & 0.9674 & 0.000182 & 98.15 & 0.997 \\
\hline 100 & 0.0126 & 36.84 & 0.9881 & 0.000122 & 78.74 & 0.998 \\
\hline
\end{tabular}

were employed to derive possible mechanism. ${ }^{36,37}$ As shown in Table 3, it was easy to find that the fitting degree $\left(R^{2}\right)$ of Langmuir model was larger than that of Freundlich model, suggesting the monolayer adsorption. ${ }^{37}$ Besides, the $Q_{\max }$ values calculated from the Langmuir isotherm and Freundlich isotherm were $77.519 \mathrm{mg} \mathrm{g}^{-1}$ and $27.613 \mathrm{mg} \mathrm{g}^{-1}$, respectively.

To analyze the kinetics of $\mathrm{Cr}(\mathrm{vI})$ adsorption onto rGO-MMT aerogel, the pseudo-first-order and pseudo-second-order models were applied at different initial concentrations of $\mathrm{Cr}(\mathrm{vI})$. According to Fig. 8 and Table 4, the correlation factors of the pseudosecond order model of all initial $\mathrm{Cr}(\mathrm{vI})$ concentrations were higher than those of the pseudo-first order model. In addition, the calculated $Q_{\mathrm{e}}$ values were well in accord with the experiments. Thus, the adsorption process of $\mathrm{Cr}(\mathrm{vI})$ onto rGO-MMT aerogel followed the pseudo-second order model, suggesting the rate limiting step was the chemisorption involving the valence force. ${ }^{37}$

Antibacterial activity. The antibacterial activities (Fig. 9) were tested against $S$. aureus and $E$. coli bacteria, which were generally considered as standard test strains for Gram-positive and Gram-negative bacteria, respectively. ${ }^{41}$ Antibacterial properties of rGO-MMT, rGO-MMT-1227 and pure 1227 were quantitatively evaluated by counting the antibacterial ratios of bacteria colonies before and after incubation for $24 \mathrm{~h}$ at $37^{\circ} \mathrm{C}$. The antiE. coli ratios treated with rGO-MMT, rGO-MMT-1227 and pure 1227 reached $53.75 \%, 80.18 \%, 91.57 \%$ and $98.25 \%$, and the counterparts were $63.39 \%, 91.51 \%, 95.53 \%$ and $99.78 \%$. The anti-E. coli and anti-S. aureus ratios of rGO-MMT were only $53.75 \%$ and $63.39 \%$, which obviously increased when 1227 was
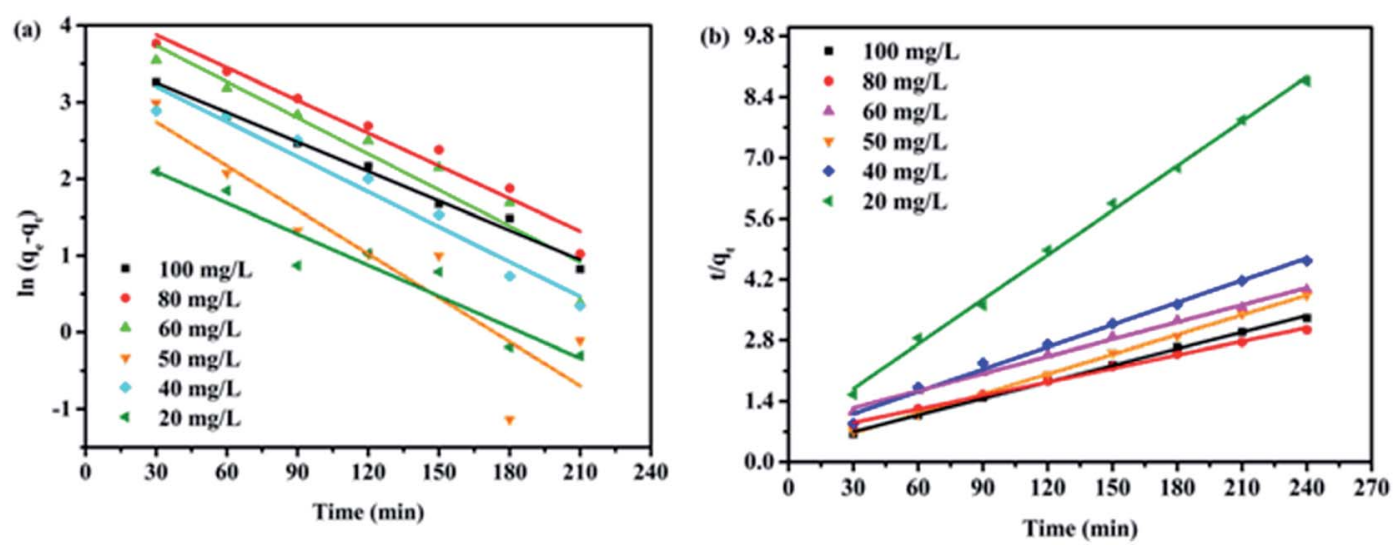

Fig. 8 Pseudo-first-order and pseudo-second-order equations in the modeling of $\mathrm{Cr}(\mathrm{vI})$ removal kinetics. 


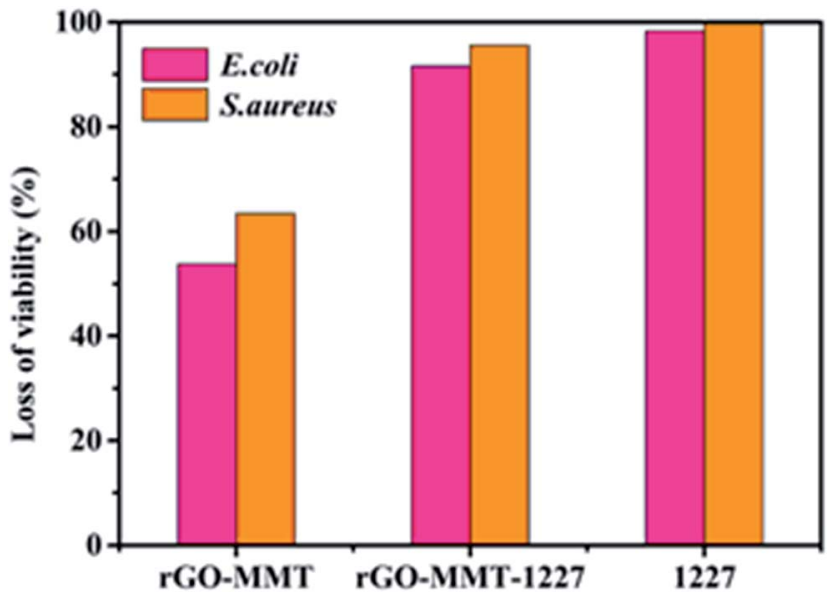

Fig. 9 Antibacterial activities of $\mathrm{rGO}-\mathrm{MMT}, \mathrm{rGO}-\mathrm{MMT}-1227$ and pure 1227.

added, suggesting that rGO-MMT could be applied as carrier to reduce the dosage of antibacterial agent.

\section{Conclusions}

MMT had been successfully embedded in layer of rGO, which was demonstrated by various characterizations. The prepared rGO-MMT had shown a porous structure and large specific surface area compared to sole rGO. According to adsorption studies, the Langmuir isotherm model and the pseudo-secondorder kinetics model could be applied to explain the adsorption mechanisms of dyes and heavy metal ions. We had proposed that the monolayer or homogeneous adsorption was dominant, and the chemisorption involving valence force was the rate limiting step. Moreover, the maximum selective adsorption capacity of MB from the mixed aqueous solution was $227.27 \mathrm{mg}$ $\mathrm{g}^{-1}$ and the adsorption capacity of $\mathrm{Cr}(\mathrm{VI})$ was $77.52 \mathrm{mg} \mathrm{g}^{-1}$. In addition, the antibacterial ratios of rGO-MMT-1227 reached $91.57 \%$ and $95.53 \%$ for $E$. coli and $S$. aureus. The prepared rGOMMT aerogel could be served as an efficient and robust material with multiple functions to handle dyes, heavy metal ions and pathogens. Therefore, the rGO-MMT aerogel was promising for water purification.

\section{Conflicts of interest}

There are no conflicts to declare.

\section{Acknowledgements}

The authors acknowledged financial support from the National Natural Science Foundation of China (21676116, 21271087 and 21476052), the Foundation of Enterprise-University-Research Institute Cooperation from Guangdong Province and the Ministry of Education of China (2015B090903072, 2015A010105019 and 2013B090600148), and the Science and Technology Innovation Platform Project of Foshan City (2015AG10020 and 2014AG100171).

\section{References}

1 X. L. Qu, P. J. J. Alvarez and Q. L. Li, Water Res., 2013, 47, 3931-3946.

2 M. T. Yagub, T. K. Sen, S. Afroze and H. M. Ang, Adv. Colloid Interface Sci., 2014, 209, 172-184.

3 L. Peng, P. F. Qin, M. Lei, Q. R. Zeng, H. J. Song, J. Yang, J. H. Shao, B. H. Liao and J. D. Gu, J. Hazard. Mater., 2012, 209, 193-198.

4 R. K. Misra, S. K. Jain and P. K. Khatri, J. Hazard. Mater., 2011, 185, 1508-1512.

5 V. C. Renge, S. V. Khedkar and S. Pandey, Sci. Rev. Chem. Commun., 2012, 2(4), 580-584.

6 M. X. Wu, J. J. Liang, J. Tang, G. Li, S. P. Shan, Z. H. Guo and L. Deng, J. Hazard. Mater., 2017, 337, 189-197.

7 S. Aoudj, A. Khelifa and N. Drouiche, Chemosphere, 2017, 180, 379-387.

8 M. Kaya, Waste Manag., 2016, 57, 64-90.

9 M. C. Tomei, D. M. Angelucci, V. Stazi and A. J. Daugulis, Sci. Total Environ., 2017, 599, 1056-1063.

10 Y. J. Juang, E. Nurhayati, C. P. Huang, J. R. Pan and S. M. Huang, Sep. Purif. Technol., 2013, 120, 289-295.

11 M. R. Awual, Chem. Eng. J., 2016, 303, 539-546.

12 D. Ocinski, I. Jacukowicz-Sobala, P. Mazur, J. Raczyk and E. Kociolek-Balawejder, Chem. Eng. J., 2016, 294, 210-221.

13 Y. D. Zou, X. X. Wang, A. Khan, P. Y. Wang, Y. H. Liu, A. Alsaedi, T. Hayat and X. K. Wang, Environ. Sci. Technol., 2016, 50, 7290-7304.

14 C. E. Barrera-Diaz, V. Lugo-Lugo and B. Bilyeu, J. Hazard. Mater., 2012, 223, 1-12.

15 J. Wu, L. M. Ma, Y. L. Chen, Y. Q. Cheng, Y. Liu and X. S. Zha, Water Res., 2016, 92, 140-148.

16 A. Abou-Shady, Chem. Eng. J., 2017, 323, 1-18.

17 S. G. Kumar and K. S. R. K. Rao, Appl. Surf. Sci., 2017, 391, 124-148.

18 O. Gimeno, J. F. Garcia-Araya, F. J. Beltran, F. J. Rivas and A. Espejo, Chem. Eng. J., 2016, 290, 12-20.

19 X. F. Yang, J. L. Qin, Y. Jiang, K. M. Chen, X. H. Yan, D. Zhang, R. Li and H. Tang, Appl. Catal., B, 2015, 166, 231-240.

20 M. Mehrjouei, S. Muller and D. Moller, Chem. Eng. J., 2015, 263, 209-219.

21 M. Hua, S. J. Zhang, B. C. Pan, W. M. Zhang, L. Lv and Q. X. Zhang, J. Hazard. Mater., 2012, 211, 317-331.

22 X. Guo, B. Du, Q. Wei, J. Yang, L. Hu, L. Yan and W. Xu, J. Hazard. Mater., 2014, 278, 211-220.

23 M. Karnib, A. Kabbani, H. Holail and Z. Olama, Energy Procedia, 2014, 50, 113-120.

24 S. Pandey, J. Mol. Liq., 2017, 241, 1091-1113.

25 Y. Q. Guo, X. Y. Sun, Y. Liu, W. Wang, H. X. Qiu and J. P. Gao, Carbon, 2012, 50, 2513-2523.

26 C. Li and G. Q. Shi, Nanoscale, 2012, 4, 549-5563.

27 J. Y. Cai, W. J. Liu and Z. H. Li, Appl. Surf. Sci., 2015, 358, 146151.

28 X. Guo, L. Qu, S. Zhu, M. Tian, X. Zhang, K. Sun and X. Tang, Water Environ. Res., 2016, 88, 768-778. 
29 K. Peng, L. J. Fu, X. Y. Li, J. Ouyang and H. M. Yang, Appl. Clay Sci., 2017, 138, 100-106.

30 D. C. Marcano, D. V. Kosynkin, J. M. Berlin, A. Sinitskii, Z. Z. Sun, A. Slesarev, L. B. Alemany, W. Lu and J. M. Tour, ACS Nano, 2010, 4, 4806-4814.

31 L. Z. Li, Z. Wang, P. M. Ma, H. Y. Bai, W. F. Dong and M. Q. Chen, J. Polym. Res., 2015, 22, 150.

32 M. H. Yeh and W. S. Hwang, Mater. Trans., 2006, 47, 27532758.

33 W. Mulewa, M. Tahir and N. A. S. Amin, Chem. Eng. J., 2017, 326, 956-969.

34 R. Boopathy, S. Karthikeyan, A. B. Mandal and G. Sekaran, Environ. Sci. Pollut. Res., 2013, 20, 533-542.

35 T. Santhi, S. Manonmani, V. S. Vasantha and Y. T. Chang, Arabian J. Chem., 2016, 9, 466-474.
36 M. A. P. Cechinel, S. M. A. G. U. de Souza and A. A. U. de Souza, J. Cleaner Prod., 2014, 65, 342-349.

37 W. Y. Huang, D. Li, Z. Q. Liu, Q. Tao, Y. Zhu, J. Yang and Y. M. Zhang, Chem. Eng. J., 2014, 236, 191-201.

38 N. Tekin, A. Safakli and D. Bingol, Desalin. Water Treat., 2015, 54, 2023-2035.

39 R. Garcia, J. Campos, J. Alfonso Cruz, M. Elena Calderon, M. Elena Raynal and G. Buitron, TIP, Rev. Espec. Cienc. Quim.-Biol., 2016, 19, 5-14.

40 T. Li, J. F. Shen, S. T. Huang, N. Li and M. X. Ye, Appl. Clay Sci., 2014, 93, 48-55.

41 A. Azam, A. S. Ahmed, M. Oves, M. S. Khan, S. S. Habib and A. Memic, Int. J. Nanomed., 2017, 7, 6003-6009. 